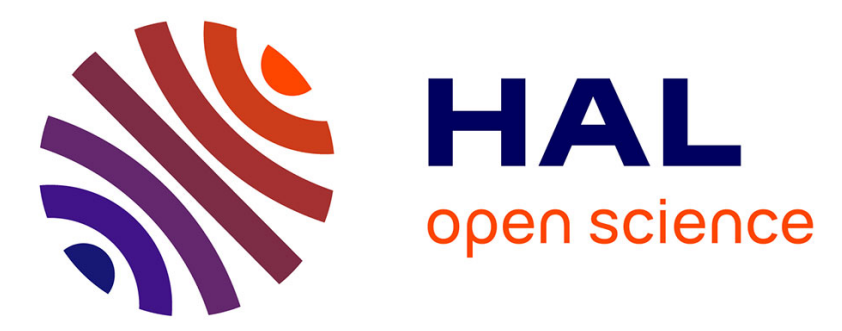

\title{
Variety Steering Towards Sustainability: A Coupled Evaluation and Optimization Approach
}

\author{
Khaled Medini, Catherine Da Cunha, Alain Bernard
}

\section{To cite this version:}

Khaled Medini, Catherine Da Cunha, Alain Bernard. Variety Steering Towards Sustainability: A Coupled Evaluation and Optimization Approach. IFIP International Conference on Advances in Production Management Systems (APMS), Sep 2014, Ajaccio, France. pp.170-177, 10.1007/9783-662-44736-9_21. hal-01387863

\section{HAL Id: hal-01387863 \\ https://hal.inria.fr/hal-01387863}

Submitted on 26 Oct 2016

HAL is a multi-disciplinary open access archive for the deposit and dissemination of scientific research documents, whether they are published or not. The documents may come from teaching and research institutions in France or abroad, or from public or private research centers.
L'archive ouverte pluridisciplinaire HAL, est destinée au dépôt et à la diffusion de documents scientifiques de niveau recherche, publiés ou non, émanant des établissements d'enseignement et de recherche français ou étrangers, des laboratoires publics ou privés. 


\title{
Variety steering towards sustainability: a coupled evaluation and optimization approach
}

\author{
Khaled Medini ${ }^{1}$, Catherine Da Cunha ${ }^{2}$, Alain Bernard ${ }^{2}$ \\ ${ }^{1}$ Ecole Nationale Supérieure des Mines de Saint Etienne, Saint Etienne, France \\ khaled.medinidemse.fr \\ ${ }^{2}$ LUNAM Université, Ecole Centrale de Nantes, IRCCyN UMR CNRS 6597, Nantes, France \\ \{catherine.da-cunha, alain.bernard\}@irccyn.ec-nantes.fr
}

\begin{abstract}
This paper proposes a coupled evaluation and optimization approach to steer product variety towards environmental and economic sustainability. A predefined set of indicators enriched with weights given by the user ensures the evaluation, while optimization uses linear programming. The paper highlights the impact of variety steering on environmental and economic sustainability indicators. Additionally, the paper underlines the need to translate regulations into concrete company goals through integrating carbon markets into the proposition.
\end{abstract}

Keywords: Variety, sustainability, evaluation, linear programming, AHP

\section{Introduction}

The broadening of customer requirements and emergence of market niches resulted in the proliferation of product variety. ElMaraghy et al. (2013) define variety as a number or collection of different things of a particular class of the same general kind. Producers seek to provide a wider spectrum of choice to gain market share and accommodate as many product variants as possible (ElMaraghy et al., 2013). However, each product variant induces a certain cost and environmental impact and generates a given profit. The challenge is to keep enough variety to meet customer requirements while steering such variety towards sustainability. The scope of current paper is focused on steering variety towards environmental and economic sustainability. It presents a coupled evaluation and optimization approach that helps managers take decisions on product variants' production volumes while considering the economic and environmental criteria. A predefined set of indicators enriched with weights reflecting each indicator's relative importance ensures the evaluation. The optimization uses linear programming to find trade-offs between all indicators while considering carbon markets.

The rest of the paper is organized as follows: section 2 provides a brief review of green supply chain performance evaluation and optimization. Section 3 presents the proposed approach comprised of indicators' weighting and optimization. Section 4 
illustrates the proposition with a case study. The paper ends with conclusions and discussion, presented in section 5 .

\section{State of the art}

\subsection{Sustainability performance evaluation}

Literature is rich in sustainability evaluation frameworks and indicators' systems. Many of them focus on the external reporting of company performance (Global Reporting Initiative, 2002; UNEP, 2009). Beyond benchmarking purposes, more methodological guidance is required to support decision makers in taking the "right" decisions on product, production process, and supply chain design alternatives. In this vein, life cycle thinking gained a lot of interest as it expanded the focus from production sites to the whole product life cycle. Life Cycle Assessment (LCA) is a method for assessing the environmental impact of product throughout its life cycle phases (ISO 14040, 2006). Dekker et al. (2012) enumerated several metric systems applied to supply chains, which, however, focused only on greenhouse gases emissions.

Recently, a comprehensive assessment model was proposed to assess sustainability performance of mass customized solutions: S-MC-S (Sustainable Mass Customization - Mass Customization for Sustainability) (Bettoni et al., 2013). The S-MC-S assessment model relies on a mixed life cycle and multi-level perspective. The life cycle aspect considers product life cycle phases (i.e. extraction, material processing, manufacturing, logistics, etc.). The multi-level aspect considers the product, production processes and supply chain levels. Indicator formulas are implemented in an assessment engine connected to the Ecoinvent ${ }^{1}$ data base which ensures more reliability of the indicator values (Pedrazzoli et al., 2012). However, a critical issue is still the high number of indicators which may compromise the decision making process. One way to address this is by aggregating indicators. The Analytic Hierarchy Process (AHP) (Saaty, 2008) is a common method that can be applied in this context.

\subsection{Green supply chains optimization}

Dekker et al. (2012) identified a lack of life cycle perspective in green operations optimization through reviewing applications of operations research to green logistics. Most studies that integrate environmental considerations into supply chain optimization focus on transportation, warehousing and inventory management (Bauer et al., 2010; Wang et al., 2011; Abdallah et al., 2012).

Moreover, laws, regulations and government action at large, are often addressed only through empirical studies that analyse their relevance to company strategies (Tan and Rae, 2009). One important achievement in this respect is the EU Emissions Trading System (EU ETS) resulting from the Kyoto Protocol. According to this system, companies receive a certain carbon emission allowance (i.e. threshold). They have to

\footnotetext{
${ }^{1}$ http://www.ecoinvent.org/
} 
buy or sell a given amount of carbon emissions according to their effective emissions during a given period of time (EP and CEU, 2009). EU ETS motivates companies to engage in sustainable development, since it compels them to jointly optimize both economic and environmental performances.

\section{Proposed approach}

The proposed approach is comprised of two steps: weighting and optimization. First step relies on interviews with company manager, while second one uses these weights for optimizing variants production volumes.

\subsection{Weighting}

Company managers weight indicators according to their priorities, using the Analytical Hierarchy Process (AHP). AHP is a widely accepted technique used in decision making. In our approach, we assume that a predefined set of $m$ indicators $I_{j}, j \in$ $\{1 . . m\}$ is already available at the company, such that $I_{j}$ is relative to one produced unit of $j$. Manager performs a pair wise comparison of the indicators during interviews. The result is the matrix $P$ (Eq. 1), where $\delta_{i j}$ is the relative importance of indicator $i$ over indicator $j$. The average value of normalized $\delta_{i j}$ (Eq. 2) results in the weight of indicator $j$ (Eq. 3).

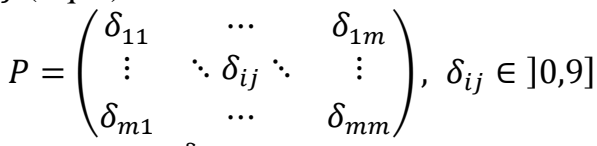

$$
\begin{aligned}
& \delta_{i j}^{n}=\frac{\delta_{i j}}{\sum_{l=1}^{m} \delta_{l j}}, i, j \in\{1 . . m, 1 . . m\} \\
& \alpha_{j}=\frac{\sum_{k=1}^{m} \delta_{j k}^{n}}{m}, j \in\{1 . . m\}
\end{aligned}
$$

In order to check the consistency of the judgements a consistency ratio (CR) is calculated according to Eq. 4. If CR is lower than 0.2 judgements are said to be consistent (Saaty, 2008).

$$
C R=\frac{\text { sum product }_{k \in\{1 . . m\}}\left[\alpha_{k}, \Sigma_{i=1}^{m} \delta_{i k}\right]-m}{R I .(m-1)}
$$

\subsection{Optimization}

Optimization aims to reduce costs and the environmental impact (and thus increase profit) by varying production volumes of product variants, these are represented by $x_{i}$. The backbone of the objective functions is indicator values $I_{j}^{i}$ such that $i$ refers to product variant and $j$ refers to the indicator, $i \in\{1 . . n\}$ and $n$ is the number of variants. We define $\gamma_{j}$, such that $\gamma_{j}=1$ if an increase of the value of indicator $j$ is desired, -1 otherwise. For each indicator $I_{j}^{i}$, an objective function $f_{j}$ is calculated as shown in Eq. 5. 


$$
f_{j}=\sum_{i=1}^{n} \gamma_{j} \cdot I_{j}^{i} \cdot x_{i}, j \in\{1 . . m\}
$$

We consider the cost/profit that can be induced by Eco taxes as follows: if the amount of greenhouse gases passes a given threshold, $T$, then company has to pay carbon tax $f_{T}$ (calculated as shown in Eq. 6). $\beta_{j}$ is a Boolean variable such that $\beta_{j}=1$ if indicator $j$ contributes to greenhouse gas emissions, 0 otherwise (Eq. 7). $C C$ is the emissions' unitary cost in the company's carbon market. When a company's emissions respect the allowed amount of emissions, it is paid by other companies where emissions exceed such a threshold.

$$
f_{T}=\mathrm{CC}\left(\sum_{j=1}^{m} \sum_{i=1}^{n} \beta_{j} \cdot I_{j}^{i} \cdot x^{i}-T\right)
$$

For optimization, we use the weighted sum scalarization technique (Ehrgott, 2013). Accordingly, the function that needs to be optimized is the weighted sum of the objective convex functions $f_{j}$. Here, we propose to use the weights $\alpha_{j}, j \in\{1 . . m\}$, given by the manager to each of the indicators $I_{j}$. The objective function can be written as in Eq. 7, where $\alpha_{c}$ is the weight of the cost indicator:

$$
\max Z=\sum_{j=1}^{m} \alpha_{j} \cdot f_{j}-\alpha_{c} \cdot f_{T}
$$

Eq. 7 can then be written as follows:

$$
\max Z=\sum_{j=1}^{m} \sum_{i=1}^{n}\left(\gamma_{j} \cdot \alpha_{j} \cdot I_{j}^{i}-\beta_{j} \cdot \alpha_{c} . C C . I_{j}^{i}\right) \cdot x^{i}+\alpha_{c} . C C . T
$$

Let $P_{\text {min }}^{i}$ and $P_{\text {max }}^{i}$ be the minimum and maximum values of possible production volumes of variant $i$, respectively (Eq. 9). Additionally let $P_{t}$ be the total production volume (Eq. 10). $P_{\text {min }}^{i}, P_{\text {max }}^{i}$ and $P_{t}$ can be determined based on expected sales and production capacity.

$$
\begin{gathered}
0 \leq P_{\text {min }}^{i} \leq x^{i} \leq P_{\text {max }}^{i} \\
\sum_{i=1}^{n} x^{i} \leq P_{t}
\end{gathered}
$$

The subsequent optimization model is as follows:

$$
\begin{gathered}
\max Z=\sum_{j=1}^{m} \sum_{i=1}^{n}\left(\gamma_{j} \cdot \alpha_{j} \cdot I_{j}^{i}-\beta_{j} \cdot \alpha_{c} \cdot C C \cdot I_{j}^{i}\right) \cdot x^{i}+\alpha_{c} \cdot C C . T \\
\text { s.t. } \\
0 \leq P_{\min }^{i} \leq x^{i} \leq P_{\max }^{i} \\
\sum_{i=1}^{n} x^{i} \leq P_{t}
\end{gathered}
$$

\section{Case study}

We applied our proposed approach to a furniture manufacturer providing several variants of customized kitchens to the luxury market. The company has three product lines. Our study involves one product line comprising 6 variants. It aims to balance the production between these variants so as to minimize the environmental impact and costs, for a given demand variation amplitude. Our approach addresses a particular aspect of product diversity by finding optimal production distribution between variants. To do so, the first step is to weight the indicators using pair wise comparisons and AHP. The second step is to solve the linear programming model to come up with a given distribution of the production volumes among variants. In current research we 
consider only weights that are calculated by AHP. This might be a burden for the optimization because we only consider a single point of the Pareto curve (depicting Pareto optimal solutions). However we base our model on the assumption that the chosen weights are most suitable to the company.

\subsection{Indicators weighting}

The predefined list of indicators used in the case study is taken from the S-MC-S assessment model (Medini et al., 2011; Bettoni et al., 2013). It is presented in Table 1. Table 2 summarizes pairwise comparisons of the indicators.

After applying AHP, subsequent weights are represented in the last row of Table 2. Consistency Ratio (CR) calculated according to Eq. 4 is 0.1542 . This value is lower than 0.2 , and judgements are then said to be acceptable. Afterwards, indicators values are calculated by an assessment engine connected to an environmental data base (Pedrazzoli et al., 2012). Data concerning the 6 variants is entered through a set of product, process and supply chain editors. Each of these variants is characterized with given material type, dimensions, shape, etc. The description of variants, however, is beyond the scope of this paper.

Table 1. Indicators definitions

\begin{tabular}{lc}
\hline Indicator & Unit of measure \\
\hline GWP - Global Warming Potential & kg eq. $\mathrm{CO}_{2}$ \\
HTP - Human Toxicity Potential & kg eq. 1,4-DCB \\
ED - Energy Depletion & $\mathrm{MJ}$ \\
NRD - Natural Resources Depletion & $\mathrm{Kg}$ antimony eq. \\
WD - Water Depletion & $\mathrm{m}^{3}$ \\
WP - Waste Production & $\mathrm{kg}$ \\
UVPC - Unitary Production Cost & $€$ \\
\hline
\end{tabular}

Table 2. Indicators pair-wise comparisons

\begin{tabular}{lccccccc}
\hline & $G W P$ & $H T P$ & $E D$ & NRD & $W D$ & $W P$ & UVPC \\
\hline$G W P$ & 1.00 & 1.00 & 1.00 & 3.00 & 0.33 & 5.00 & 0.20 \\
$H T P$ & 1.00 & 1.00 & 5.00 & 3.00 & 1.00 & 7.00 & 3.00 \\
$E D$ & 1.00 & 0.20 & 1.00 & 3.00 & 0.33 & 3.00 & 0.33 \\
NRD & 0.33 & 0.33 & 0.33 & 1.00 & 0.33 & 0.33 & 0.20 \\
$W D$ & 3.00 & 1.00 & 3.00 & 3.00 & 1.00 & 3.00 & 0.33 \\
$W P$ & 0.20 & 0.14 & 0.33 & 3.00 & 0.33 & 1.00 & 0.33 \\
UVPC & 5.00 & 0.33 & 3.00 & 5.00 & 3.00 & 3.00 & 1.00 \\
Weights & $\mathbf{0 . 1 2}$ & $\mathbf{0 . 2 7}$ & $\mathbf{0 . 0 9}$ & $\mathbf{0 . 0 4}$ & $\mathbf{0 . 1 8}$ & $\mathbf{0 . 0 5}$ & $\mathbf{0 . 2 5}$ \\
\hline
\end{tabular}

\subsection{Optimization}

The function that needs to be minimized is represented by Eq. 11 to 13, where $i$ is the variant, with $i \in\{1,2,3,4,5,6\}$. We propose the use of another indicator, Cost, that includes $U V P C$ and cost incurred by the case company in the carbon market. We introduce an income indicator as depicted by Eq. 15. Let 1500 be the amount of greenhouse gases $(T)$ the case company can emit in a given carbon market, 30 be the emis- 
sions unitary cost $(C C)$ and 150 be the total production volume $\left(P_{t}\right)$. GWP is the only indicator that represents greenhouse gases emissions.

$$
\begin{gathered}
\max Z=\sum_{i=1}^{6}\left(\alpha_{H T P} \cdot H T P^{i}+\alpha_{E D} \cdot E D^{i}+\alpha_{N R D} \cdot N R D^{i}+\alpha_{W D} \cdot W D^{i}+\alpha_{H T P} \cdot W P^{i}+\right. \\
\left.\alpha_{U V P C} \cdot U V P C^{i}-\alpha_{G W P} \cdot 30 . G W P^{i}\right) \cdot x^{i}+\alpha_{U V P C} \cdot 30.1500 \\
\text { s.t. } \\
6 \leq x^{i} \leq 10 \text { if } i \in\{1,2,3,4\} \\
60 \leq x^{i} \leq 64 \text { if } i \in\{5,6\} \\
\sum_{i=1}^{6} x^{i} \leq 158
\end{gathered}
$$

Indicators values and production volumes are represented in Table 3. Minimum $\left(P_{\min }^{i}\right)$ and maximum $\left(P_{\max }^{i}\right)$ production volumes are defined. Their values shown in Table 3 are chosen based on average data from the case company.

Table 3. Variants data

\begin{tabular}{cccccccccc}
\hline Variants & & \multicolumn{3}{c}{ Indicators } & \multicolumn{3}{c}{ Production } \\
& GWP & HTP & ED & NRD & WD & WP & UVPC & $P_{\min }^{i}$ & $P_{\max }^{i}$ \\
\hline 1 & 20.95 & 11.71 & 1368.3 & 0.19 & 0.17 & 2.00 & 11.21 & 6 & 10 \\
2 & 23.56 & 16.87 & 1485.2 & 0.22 & 0.19 & 2.27 & 13.41 & 6 & 10 \\
3 & 22.84 & 16.69 & 1444.4 & 0.21 & 0.18 & 2.27 & 14.35 & 6 & 10 \\
4 & 22.36 & 12.53 & 1471.4 & 0.21 & 0.18 & 2.14 & 13.80 & 6 & 10 \\
5 & 23.07 & 12.84 & 1518.2 & 0.22 & 0.19 & 2.18 & 16.10 & 60 & 64 \\
6 & 22.10 & 12.57 & 1466.4 & 0.21 & 0.18 & 2.15 & 14.86 & 60 & 64 \\
\hline
\end{tabular}

The linear programming problem is solved using Microsoft Office Excel solver and by choosing Simplex method. We varied $\Delta_{i}$ in order to check the impact of production volume variance on the indicators. Table 4 shows the results obtained for different values of $\Delta_{i}$ such that $\Delta_{i}=P_{\max }^{i}-P_{\min }^{i}$. Columns 3 to 10 represent the sum of indicators among all variants. The first row of the table relates to the standard ( $\mathrm{Sd})$

\begin{tabular}{|c|c|c|c|c|c|c|c|c|c|c|c|c|c|c|c|}
\hline \multirow{2}{*}{$\Delta_{V}$} & \multirow{2}{*}{$\begin{array}{l}P_{\min }^{1}, \\
P_{\min }^{2}, \\
P_{\min }^{3}, \\
P_{\min }^{4},\end{array}$} & \multirow{2}{*}{$\begin{array}{c}P_{\min }^{5} \\
P_{\min }^{6}\end{array}$} & \multicolumn{7}{|c|}{ Indicators values } & \multicolumn{6}{|c|}{ Decision variables } \\
\hline & & & GWP & HTP & ED & NRD & WD & WP & Cost & $x^{1}$ & $x^{2}$ & $x^{3}$ & $x^{4}$ & $x^{5}$ & $x^{6}$ \\
\hline$\overline{\mathrm{Sd}}$ & 8 & 63 & 3563 & 2063 & 234184 & 33.73 & 29.07 & 342 & 64274 & 8 & 8 & 8 & 8 & 63 & 63 \\
\hline 4 & 6 & 60 & 3248 & 1871 & 213691 & 30.78 & 26.52 & 312 & 54628 & 6 & 6 & 6 & 6 & 60 & 60 \\
\hline 8 & 4 & 58 & 2979 & 1705 & 196184 & 28.26 & 24.34 & 286 & 46368 & 4 & 4 & 4 & 4 & 58 & 58 \\
\hline 12 & 2 & 56 & 2709 & 1539 & 178676 & 25.74 & 22.16 & 260 & 38108 & 2 & 2 & 2 & 2 & 56 & 56 \\
\hline
\end{tabular}
situation within the case study, that is: $P_{\min }^{i}=P_{\max }^{i}=8, i \in\{1,2,3,4\}$ and $P_{\text {min }}^{i}=$ $P_{\text {max }}^{i}=63, i \in\{5,6\}$. Optimal solution fitting such standard situation is as follows: producing 8 units of each of variants 1 to 5 and 63 units of each of variants 5 and 6 . Data relating to this situation are described in detail in Table 3.

Table 4. Production volumes variance impact on indicators $\left(\sum_{i=1}^{6} x^{i} \leq 158, T=1500\right)$

As shown, in Table 3, all indicators values decrease with the increase of the gap between minimum and maximum production volumes of each variant $i$. Such a decrease is expected, since the model has as many options as the interval of decision variables (production volumes of the variant) increases. It is then more likely to find more optimal solutions. The manager, for instance, can select one of the proposed solutions according to the production system capacity that determines which $\Delta_{i}$ the company can afford. The trend that can be noticed in the solutions offered by the 
model (i.e. decision variables) values is the minimization of total production volumes of the variants. The lower the variant minimal production volume, the lower is total production volume. Figure 1 shows the variation of the income for different carbon market threshold values, with:

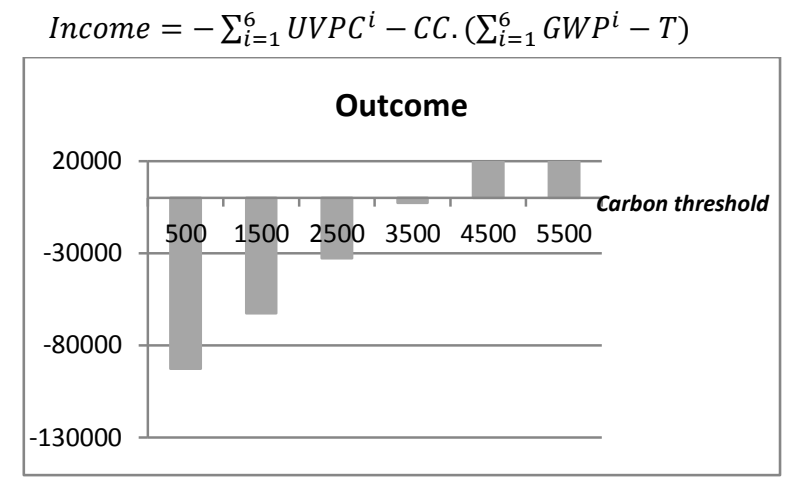

Fig. 1. Carbon threshold impact on income

Company's greenhouse gases emissions amount to approximately $3500 \mathrm{~kg}$. Thus, it incurs a carbon cost until the threshold exceeds this value, then revenue is generated by the reimbursement to the company for the non-emitted but allowed amount of greenhouse gases. This highlights the importance of considering the carbon market in the optimization of the economic and environmental performance of the company.

\section{Conclusions}

In this paper we propose a combined evaluation and optimization approach to mitigate variety impact on sustainability. The evaluation relies on sustainability performance indicators connected to an external environmental data base. Indicators are weighted according to company priorities, thus providing more decision support to managers. Optimization aims to minimize emissions and cost through balancing production volumes between variants and integrating the carbon market. Production capacity and demand are considered at this point. The originality of our approach lies in coupling performance evaluation and optimization. Moreover, the indicators used in the evaluation consider product life cycle phases (i.e. extraction, manufacturing, transportation, etc.).

The paper underlines the impact of variety steering on sustainability indicators. When the variants' production volumes are flexible, the cost and environmental impact are lower. Furthermore, the paper points out the relevance of the carbon market to company environmental and economic performances. From this, it follows that environmental considerations should be considered from a win-win perspective rather than an external constraint. In this sense optimizing company sustainability performance generates economic value (e.g. reimbursement from the carbon market) instead of making companies incur additional costs. 


\section{References}

1. Abdallah, T., Diabat, A., Simchi-Levi, D., 2012. Sustainable supply chain design: a closed-loop formulation and sensitivity analysis, Production Planning \& Control, 23(2-3), 120-133.

2. Bauer, J., Bektas, T., and Crainic, T.G., 2010. Minimizing greenhouse gas emissions in intermodal freight transport: an application to rail service design. Journal of the Operational Research Society, 61, 530-542.

3. Bettoni, A., Corti, D., Fontana, A., Zebardast, M., and Pedrazzoli, P., 2013. Sustainable Mass Customization Assessment, in: Carneiro L.M., Jasinski T., Zolghadri M., Pedrazzoli P.(Ed.), Intelligent Non-hierarchical Manufacturing Networks, John Wiley \& Sons, Inc., 249-276.

4. Dekker, R., Bloemhof, J., and Mallidis, I., 2012. Operations research for green logistics - an overview of aspects, issues, contributions and challenges, European Journal of Operational Research, 219(3), 671-679.

5. ElMaraghy, H., Schuh, G., ElMaraghy, W., Piller, F., Schönsleben, P., Tseng, M., and Bernard, A. 2013. Product Variety Management, CIRP Annals - Manufacturing Technology, 62(2), 629-652.

6. European Parliament (EP) and Council of the European Union (CEU) (2009). Directive 2009/29/EC of the European parliament and of the council of 23 April 2009. Official Journal of the European Union. Online, accessible from : http://eur-lex.europa.eu/LexUriServ/LexUriServ.do?uri=OJ:L:2009:140:0063:008 7:EN:PDF.

7. Ehrgott, M. A, 2013. A discussion of scalarization techniques for multiple objective integer programming. Annals of Operations Research, 147(1),343-360.

8. Global Reporting Initiative, 2002. Sustainability reporting guidelines, Global Reporting Initiative, Boston, USA.

9. ISO 14040 (2006). Environmental Management - Life Cycle Assessment Principles and Framework. International Organization of Standardization.

10. Jorgensen, A., Le Bocq, A., Nazarkina, L., and Hauschild, M., 2008. Methodologies for social life cycle assessment. International Journal of Life Cycle Assessment, 13(2), 96-103.

11. Medini, K., Bettoni, A., Fontana, A., Corti D., and Zebardast, M., 2011. S-MC-S - D3.1 Assessment Model, European Commission, 507p.

12. Pedrazzoli, P., Alge, M., Bettoni, A., Canetta, L., 2012. Modeling and Simulation Tool for Sustainable MC Supply Chain Design and Assessment, In: Proc. of APMS 2012, Rhodes, Greece.

13. Saaty, T. L., 2008. Decision making with the analytic hierarchy process, International Journal Services Sciences, 1(1), 83-98.

14. Tan, K.H., and Rae, R.H., 2009. Uncovering the links between regulation and performance measurement, International Journal of Production Economics, 122(1), 449-457.

15. United Nations Environment Programme (UNEP), 2009. Life Cycle Management: A Business Guide to Sustainability. Online, accessible from: http://www.unep.org/pdf/dtie/DTI0889PA.pdf.

16. Wang, F., Lai, X., and Shi, N., 2011. A multi-objective optimization for green supply chain network design, Decision Support Systems, 51 (2), 262-269. 